\title{
La comunicación de los profesionales del deporte
}

\author{
Oleguer CAMERINO FOGUET \\ Marta CASTAÑER BALCELLS
}

Somos tanto una respuesta a los estímulos de la gente como un estímulo para su conducta.

Bateson, 1984.

\section{INTRODUCCIÓN}

La observación sobre la práctica del deporte nos ofrece la posibilidad del análisis de un sinfin de procesos comunicativos que se deducen de los gestos actitudes e interacciones que se establecen entre los técnicos y profesionales del deporte. La variabilidad espacial y temporal de la expresión del movimiento deportivo nos lleva a una gran riqueza de interpretación.

Existen dos tendencias en relación a la búsqueda de significación de las comunicaciones en el deporte: primero, aquellas explicaciones que intentan explicar el fenómeno comunicativo en el deporte desde un punto de mira externo; segundo, explicaciones que quieren comprender internamente el fenómeno, teniendo en cuenta sus motivaciones.

Desde estas dos perspectivas de la realidad itentaremos una reflexión elaborada de ideas y conceptos significativos que son necesarios para ayudar a emerger el potencial expresivo de los técnicos deportivos. 


\section{MARCO TEÓRICO: EL ESTUDIO DE LA COMUNICACIÓN DE LOS TÉCNICOS DEPORTIVOS}

La mayoría de los estudios de observación, análisis e investigación de situaciones en las que entra en juego la motricidad -deportiva, educativa, lúdica, expresiva- han estado orientadas, en demasía, a comprobar elementos fácilmente cuantificables. Así, en el ámbito deportivo más estricto, se suelen observar básicamente acciones y habilidades específicas a cada disciplina deportiva, aspecto que hoy en día no revierte mucho misterio al hallarse al alcance de cualquier espectador $\mathrm{u}$ oyente de los medios de comunicación encargados de ofrecer todo tipo de cifras cuantitativas de acciones (número de corners, de posesiones de balón) y de análisis de estrategia de juego sobre imágenes registradas y ralentizadas.

El empeño investigador que estamos llevando a cabo en el Laboratorio de Observación Educativa del Instituto Nacional de Educación Física de Cataluña (INEFC) en la última década, nos ha llevado a la obtención de variables observables básicas y de indicadores para la optimización del discurso del educador de la motricidad. Nos centramos en el análisis de variables de comunicación verbal y no verbal de tipo cinésico y proxémico, de las conductas observables y latentes que revisten el transcurso de cualquier discurso y actuación pedagógica.

Usamos una metodología de integración en nuestros diseños de investigación que conlleva el tratamiento y la consideración de una pluralidad de datos cualitativos y cuantitativos (Camerino, 1996). Junto al uso de instrumentos semisistematizados como las entrevistas, historias de vida y diarios personales, el instrumento más potente con que contamos, y alrededor del cual gira todo lo demás, son los sistemas categoriales que hemos construido. Éstos son un medio de análisis útil, flexible y muy aplicable en el análisis de la comunicación verbal, cinésica y gestual de técnicos deportivos.

El perfil de la intervención del entrenador se suele definir, en el ámbito del deporte, en función de la distribución y la cuantificación de sus conductas comunicativas. Los sistemas categoriales de observación se articulan generalmente alrededor de las funciones de vehiculación de los contenidos (información, demostración, explicación...), de organización, de feed-back de comportamiento y períodos de observación "silenciosa" de la tarea de los alumnos. 
Las categorias de acción que hemos mencionado son categorias que se han de molecularizar mucho más, ya que contemplar un perfil general de las intervenciones del educador nos lleva tan sólo a una cuantificación de las funciones más generales de la tarea docente. Vamos a ver algunos de los parámetros que utilizamos en el estudio de la comunicación del educador.

\section{Intervenir implica influenciar}

Por mínima e insignificante que sea una intervención en el ámbito del deporte siempre existe algún grado de influencia por parte del entrenador. Una intervención eficaz implica la superación de obstáculos tanto psicológicos como sociales de los deportistas.

Si nos ponemos a analizar toda la gama de estilos del entrenador y de sus intervenciones, la tarea de su intervención interactiva viene protagonizada por su rol comunicativo. Se trata de un rol fundamental tanto dentro del proceso de aprendizaje como dentro de la conducción del equipo; entendido como un amplio y versátil conjunto de experiencias, puestas en común en procesos de aprendizaje y desarrollo que, ya sea de forma continua como puntualmente, van definiendo la dinámica del grupo.

Así, pues, para que un estilo de intervención pueda ser cualificado de interactivo ha de responder a determinadas directrices, por no decir exigencias. En el caso concreto de las tareas de mejora de perfeccionamiento deportivo que hemos llevado a cabo en nuestra experiencia, las directrices básicas que las podrian definir son las siguientes:

- El educador ha de saber reflexionar sobre cuales serán los matices de su rol: animador, supervisor, técnico, informador, consejero.

- El educador ha de proceder a un análisis de los intereses, deseos y preocupaciones posibles que entran en juego en el grupo sobre el cual ha de intervenir.

- El educador ha de saber combinar la selección de las actividades con la capacidad de propuesta y de estimulación para que el grupo proponga y encuentre tipos de actividades a desarrollar.

- El educador ha de estar siempre en situación de poder ofrecer la información necesaria que requieren los miembros del grupo sobre el cual interviene.

- El educador ha de tener siempre a su alcance estra- 
tegias y técnicas teórico-prácticas como herramientas, tanto para optimizar la dinámica y los aprendizajes del grupo, como para garantizar la propia observación y valoración del proceso y de los productos, fruto de la interacción pedagógica establecida.

\section{METODOLOGÍA DE TRABAJO ¿CÓMO ESTUDIAMOS LA COMUNICACIÓN?}

En nuestros trabajos abordamos dos sistemas de categorias, uno para analizar la conducta verbal y otro para analizar la no verbal. Ambos sistemas de categorias eran una adaptación de los que se utilizaron en una experiencia similar (Camerino \& Pradas, 1996) en donde, a grandes rasgos, se analizaba y se categorizaba de manera sistemática la conducta comunicativa, tanto en la dimensión verbal como no verbal, de profesores de educación fisica, durante su acción docente.

Como a continuación podrá observarse, nuestro sistema de categorías se vertebra en base a dos categorías molares: el comportamiento comunicativo verbal con y sin significación lógica, y el comportamiento comunicativo no verbal. Estos grupos molares están compuestos por categorias más pequeñas o "moleculares" que serán las que se irán registrando como unidades conductuales observables. Por este motivo, a continuación describiremos todas y cada una de dichas categorias moleculares (Castañer, 1992; Castañer, 1996; Camerino, 1994 y Camerino, 1996).

Definiremos a continuación las categorias que usamos para nuestro estudio:

- Comportamiento comunicativo verbal con y $\sin$ significación lógica:

- Órdenes, mandatos y disposiciones organizativas (ORD).

- Explicaciones (EX).

- Paralenguajes (PL).

- Preguntas y respuestas (P/R).

- Comportamientos afectivos (A+/A-).

- Comportamientos comunicativos no verbales:

- Explicaciones (EX).

- Reguladores (REG).

- Adaptadores (ADAP).

- Ilustradores (ILUS).

- Participaciones y demostraciones (PA.DE).

- Muestras de afecto (MA).

- Observación (OBS).

- Conjunto vacío 
- Comportamientos comunicativo verbal con y sin significación lógica:

- Órdenes, mandatos y disposiciones organizativas (ORD): comportamientos del profesor que pretenden canalizar de manera intencionada la dinámica del grupo en relación a cuestiones organizativas, disciplinarias y de control o supervisión de la clase. Podemos incluir aquí las voces de inicio y final de una actividad, los mensajes que pretenden llamar la atención de uno o varios alumnos y las consignas para reclamar un tipo de distribución por el espacio necesario para el desarrollo de la actividad.

- Explicaciones (EX): comportamientos comunicativos verbales del docente por medio de los cuales se transmite información acerca de las tareas y cómo poder llevar a cabo las mismas. E1 profesor es el que inicia el intercambio comunicativo, incluyendo en su mensaje las indicaciones necesarias para la mejora de la tarea, que no tienen que requerir una respuesta inmediata de los alumnos y que pueden ser tomadas como elementos técnicos de mejora de la tarea.

- Paralenguajes (PL): expresiones que no tienen significación lógica para el alumno. Incluye sonidos que el educador emite como expresión de sentimientos y frases o palabras dirigidas a sí mismo; "coletillas" o reiteración de vocablos emitidos durante su discurso (bueno, ehhh...) y cuestiones planteadas por el profesor sin esperar la respuesta del alumno (¿Vale?; ¿sí?; ¿de acuerdo?...).

- Preguntas y respuestas $(P / R)$ : aquí se incluyen tanto aquellos intercambios comunicativos en relación a las actividades de enseñanza-aprendizaje que surgen como iniciativa del profesor y que inducen al alumno a una respuesta, de tipo verbal, más o menos inmediata, como las emisiones verbales que pretenden responder a preguntas de sus alumnos.

- Comportamientos afectivos $(A+/ A-)$ : conductas del profesor cuya finalidad principal es crear un clima afectivo en la clase favorable para el aprendizaje (muestras de ánimo; reforzadores positivos; expresiones de aprobación; bromas...) o conductas del profesor que en forma de repri- 
menda, tienen una repercusión negativa a nivel afectivo, impidiendo una relación cordial y de confianza entre profesor y alumno.

- Comportamientos comunicativos no verbales.

- Reguladores (REG): signos que sirven para controlar y encadenar los momentos de intercambio comunicativo entre el educador y los alumnos, solicitando de ellos una respuesta inmediata. Dichas conductas pueden darse de manera concurrente en el tiempo con los comportamientos englobados dentro de la categoría de observación.

- Adaptadores (ADAP): movimientos y posiciones del docente en que ciertas partes del cuerpo entran en contacto con otras partes de sí mismo, con alguna otra persona o con el entorno objetual más próximo. Su uso es habitualmente inconsciente y no se producen con una intencionalidad comunicativa clara.

- Ilustradores (ILUS): movimientos del profesor que están directamente vinculados a la palabra y que tienen la función de dar soporte al discurso verbal, e incluso de poner énfasis en diversos apartados del mismo. Dichas conductas pueden darse de manera concurrente en el tiempo con los comportamientos englobados dentro de la categoria de observación.

- Participación y demostración (PADE): incluye la participación activa del profesor, integrado en las tareas propuestas como un alumno más, así como aquellos movimientos que están destinados a mostrar con claridad el modelo, las habilidades que son necesarias para llevar a cabo un cometido determinado.

- Muestras de afecto (MA): gesticulaciones del profesor que expresan de una manera intencionada un estado emocional o sentimiento del educador hacia el educando.

- Observación (OBS): situaciones en las que el profesor observa, de forma estática o dinámica, el funcionamiento de las actividades y las evoluciones de los alumnos durante las mismas. Pueden darse de manera concurrente en el tiempo con los comportamientos comunicativos verbales del docente. 
- Conjunto vacío: aquí se registran los momentos en donde se produce una ausencia de cualquiera de las categorias que configuran nuestro sistema.

Por otro lado, y en lo referente al proceso de categorización de las sesiones, señalar que dicho proceso era llevado a cabo inmediatamente después de que la sesión fuese registrada en vídeo. De esta manera realizamos una reunión de supervisión, una vez que su actuación había finalizado. Este análisis nos permitía disponer de datos para la comparación de diferentes docentes y para su mejora profesional. 
Bibliografía

Bateson, G y J. Ruesch 1984

La nueva comunicación. Barcelona: Paidós.

Camerino, O.

1992

"La interacción educativa en la actividad físico-recreativa para la tercera edad. Un análisis de integración metodológica”. Tesis doctoral publicada por la Universidad de Barcelona.

Camerino, O. y M. Pradas 1996

La entrevista rememorada en la formación inicial de los docentes de educación física. INEFC-Lleida.

Castañer, M.

1992

La comunicación no-verbal del educador físico: construcción de un sistema categorial de observación y de análisis del comportamiento cinésico. Tesis Doctoral publicada de la Universidad de Barcelona.

Castañer, M. y O. Camerino 1992

Unidades didácticas para primaria I. Colección la educación Física en Reforma. Barcelona: Inde.

1996

La educación física en la educación primaria. Colección la Educación Física en Reforma, 3a. edición. Barcelona: Inde.

Castañer, M. y E. Trigo 1995

La interdisciplina curricular en la enseñanza primaria. Propuestas teórico-prácticas. Barcelona: Inde.

1995 La interdisciplinariedad en la enseñanza secundaria. Propuestas teórico-prácticas. Barcelona: Inde. 
Ekman, P. (comp.)

1976

Fromont, M.F.

1981

Frostig, M. y P. Maslow 1984

Jousse, M.

1974

Marías, J.

1987

Motos, T.

1983

Neruda, P.

1978

Paquette, C.

1992

Pieron, M.

1986

Pouillart, G.

1989
"Body Movement and Voice Pitch in Deceptive Interaction". Semiotica, 16: 1,23-27.

El mimetismo en el niño. Barcelona: Herder.

Educación del movimiento. Teoría y práctica. Buenos Aires: Panamericana.

L'anthropologie du geste. Mayenne: Gallimard.

Antropologia metafisica. Madrid: Alianza Universidad.

Iniciación a la expresión corporal. Madrid: Humanitas.

Veinte poemas de amor y una canción desesperada. Buenos Aires: Losada.

Une pedagogie ouverte et intéractive, Québec: Québec-Amérique.

Enseñanza de las actividades físicas y deportivas, observación e investigación. Málaga: Unisport.

Las actividades fisicas y deportivas. Enseñar, estimular, entrenar. Barcelona: Paidós-MEC.

Watzlawick, P., J. Helmick y D.D. Jackson 1983

Teoría de la comunicación humana.

Barcelona: Herder. 